\title{
HIV infection among heterosexual travellers attending the Hospital for Tropical Diseases, London
}

Sarah Hawkes, Adam Malin, Trish Araru, David Mabey

\begin{abstract}
Objective-To determine the prevalence of HIV infection in travellers attending the Hospital for Tropical Diseases, London, and to assess correlates and behavioural risk factors for infection.

Design-All patients tested for HIV infection during a 28-month period were included. Information was obtained from clinical records and standardised serological request forms.

Setting-Hospital for Tropical Diseases, London, UK

Subjects-298 patients (in-patient and out-patient) were tested.

Results-258 of those tested were exclusively heterosexual and not injecting drug users. $5 \cdot 4 \%$ of these were HIV-1 antibody positive. Rates in those originating from the UK and those from outside the UK were $1.8 \%$ and $33.2 \%$ respectively. Most non-UK citizens were symptomatic when tested; UK citizens were generally tested as part of a routine screening, therefore the two groups are not comparable. Rates of risk behaviour were high in both groups. Conclusion-The rate of HIV infection in heterosexual travellers was $5 \cdot 4 \%$. Amongst UK citizens the rate was $\mathbf{1 \cdot 8 \%}$. All travellers should be made aware of the potential risk of acquiring HIV infection through sexual contact.
\end{abstract}

\section{Introduction}

The proportion of HIV infections reported in England, Wales and Northern Ireland which were believed to be acquired through heterosexual contact has increased from $4 \%$ in 1986 to $23 \%$ in $1991 .^{1}$ A striking increase in HIV seroprevalence among pregnant women was documented in a recent study in which antenatal clinic attenders were tested anonymously; approximately 1 in 200 were found to be infected in one London clinic. ${ }^{2}$

Recent reports from genitourinary medicine clinics in and near London have suggested that this increase is largely attributable to immigrants or refugees from countries with a high HIV seroprevalence, since most HIV infected heterosexual patients identified at these clinics came from these countries. ${ }^{3-7}$ Given the fact that most heterosexuals of UK origin are not tested for HIV at such clinics, it is possible that selection bias accounts at least in part for the higher number of HIV infected subjects identified among patients originating from overseas. The assumption that heterosexual transmis- sion of HIV is rare among citizens of this country may lead to unjustified complacency and failure to promote safer sexual practices among heterosexuals at risk.

By the end of $1991,79 \%$ of heterosexually infected AIDS cases reported to the Communicable Disease Surveillance Centre (CDSC) were presumed to have been infected abroad, and the corresponding figure for reported HIV infections was $74 \%{ }^{1}$ Such reports do not distinguish between those originating from abroad, expatriates resident overseas on a long term basis and short term travellers, such as holidaymakers.

Although there have been several case reports of UK residents infected through heterosexual contact overseas, ${ }^{89}$ the lack of appropriate numerators and denominators has precluded an estimation of the risk of HIV infection among heterosexual travellers from the UK. We report here the travel history and risk factors of HIV seropositive and seronegative heterosexual travellers seen at the Hospital for Tropical Diseases, London over a 28 month period.

\section{Methods}

Since 1988, all outpatients attending the Hospital for Tropical Diseases, London have been informed that HIV testing is available. Virtually all these patients have travelled within the previous year to a tropical or subtropical country. Many of them are asymptomatic and attend for a routine "post-tropical check" to exclude the presence of infections or infestations contracted during their travels. Others present for the investigation of illness possibly acquired abroad. A standard medical history, including sexual and other risk behaviours for HIV infection, is taken from each patient before blood is taken. Those requesting an anti-HIV test, and those considered by the examining doctor to be at risk of infection, have been given standard pre- and post-test counselling.

Between May 1988 and September 1990, 298 patients were tested out of a total of 5980 new patients seen. Of these, 258 were exclusively heterosexual and had no history of injecting drug use. Risk factors for heterosexual patients were assessed retrospectively from clinical records and a standardised serological request form. HIV testing was carried out by Wellcozyme HIV 1+2 (Wellcome Diagnostics) and confirmed by Wellcozyme HIV recombinant assay and an Abbott HIV recombinant assay (Abbott Diagnostics). 


\section{Results}

Two hundred and ninety-eight subjects were tested. Of these, 27 were homosexual or bisexual and 13 had injected drugs. The prevalence of HIV 1 seropositivity in these groups was $33.3 \%(9 / 27)$ and $0 \%(0 / 13)$ respectively. Two hundred and fifty-eight exclusively heterosexual subjects who had not injected drugs were tested, of whom 14 (5.4\%) were HIV 1 antibody positive. No subjects were found to be infected with HIV-2.

As shown in the table, heterosexual subjects having an HIV test at the hospital could be placed in three categories: (1) Travellers; those who had spent less than 2 years overseas. (2) Workers; those who had worked overseas for 2 years or more. (3) Those who originated from WHO Pattern II countries. Assessing the behaviour of both the travellers and workers, two main risk factors emerge: (a) $94 / 155$ travellers (60.6\%) and $16 / 71$ workers (22.5\%) reported having multiple sexual partners; (b) $113 / 155$ travellers $(72 \cdot 9 \%)$ and $40 / 71$ workers $(56.3 \%)$ had one or more sexual partners from a country in which HIV was transmitted mainly by heterosexual contact.

The HIV 1 seroprevalence rates are given for these three categories of subject in the table. The overall seroprevalence of HIV 1 infection among those originating from the UK was $4 / 226(1 \cdot 8 \%)$. Amongst these UK patients, $154 / 226(68 \cdot 1 \%)$ had visited sub-Saharan Africa, 18/226 (7.9\%) Thailand, and 54/226 $(23.9 \%)$ other developing countries . All four UK seropositive patients had visited subSaharan Africa. Of 32 patients originating from overseas, 31 were from sub-Saharan Africa and the remaining 10 seropositives fell into this group. All 10 were tested because they had symptoms which could be attributable to HIV infection.

Information concerning the use of condoms was available from 74 subjects. The prevalence of HIV 1 seropositivity did not differ significantly between those who reported using condoms $(1 / 14,7 \cdot 1 \%)$ and those who did not $(5 / 60,8 \cdot 3 \%)$. Fourteen men reported paying for sex, one of whom was HIV 1 positive $(7 \cdot 1 \%)$

\section{Discussion}

The prevalence of HIV 1 infection among travellers and expatriates originating from the UK in this study $(1.8 \%)$ is similar to that found among Belgian expatriates working in Africa by Bonneux et al at an earlier stage of the epidemic. ${ }^{10}$ Forty-one of $4564(0.9 \%)$ Euro- pean expatriates were seropositive; risk factors for seropositivity were: having multiple local sexual partmers, contact with prostitutes, injections by unqualified staff and a low educational level. In the Belgian study all expatriates presenting for an occupational medical examination were tested for HIV. Our study is confined to the proportion of patients who either requested screening or were advised to have an HIV test by the examining doctor.

In view of the fact that more than 30 million visits overseas are made by UK citizens annually, including 2 million to the USA and 600,000 to Africa, ${ }^{11}$ our finding of an HIV prevalence rate of over $1 \%$ among heterosexual travellers is indeed a cause for concern. A possible source of bias is that patients attending the HTD are an atypical group of travellers, but they are perhaps more likely than others to be aware of the health risks associated with travel, and therefore less likely to put themselves at risk of HIV infection.

A recent study has documented a lower seroprevalence among Dutch expatriates working in sub-Saharan Africa. ${ }^{12}$ Four of 1122 $(0 \cdot 4 \%)$ men and one of $846(0.1 \%)$ women were infected with HIV 1. Four of the five seropositive individuals had multiple local partners and had been treated for other sexually transmitted diseases (STDs). The authors of this paper noted that unprotected sex with casual partners was commonly reported.

The efficacy of health education in preventing HIV infection is demonstrated by a recent study among American Peace Corps volunteers in Zaire. ${ }^{13}$ No seropositive subject was found among 282 volunteers serving in Zaire between 1985 and 1988, representing 7776 volunteer months of service. During the study period the incidence of other STDs fell from 131 to 68 per 1000 study population per year, confirming the widespread adoption of safer sexual practices.

In the present study the prevalence of HIV infection among subjects originating from subSaharan Africa was higher than that among those originating from the United Kingdom $(10 / 31(32 \cdot 3 \%)$ compared with $4 / 226(1 \cdot 8 \%))$. However, African patients referred to this hospital are often symptomatic, whereas many returning expatriates and travellers have no symptoms and are referred at their own request for a routine "post-tropical screen". The two groups are therefore not comparable.

A recent survey conducted at this hospital among attenders for pre-travel health advice found that $104 / 110$ (95\%) knew that HIV

Table Risk behaviour rates for HIV infection in heterosexuals

\begin{tabular}{|c|c|c|c|c|}
\hline \multirow[b]{2}{*}{ Risk activity } & \multicolumn{4}{|c|}{ Travel category $(x / n)^{*}$} \\
\hline & Travellers & Worked abroad & $\begin{array}{l}\text { Originates from Pattern II } \\
\text { country }\end{array}$ & Total \\
\hline $\begin{array}{l}\text { Multiple sexual partners } \\
\text { Partner from pattern II country } \\
\text { Tested for investigation of current illness } \\
\text { Total HIV positive }\end{array}$ & $\begin{array}{l}2 / 94(2 \cdot 1 \%) \\
2 / 113(1 \cdot 8 \%) \\
2 / 29(6 \cdot 9 \%) \\
2 / 155(1 \cdot 3 \%)\end{array}$ & $\begin{array}{l}0 / 16(0 \%) \\
2 / 40(5 \%) \\
0 / 12(0 \%) \\
2 / 71(2 \cdot 8 \%)\end{array}$ & $\begin{array}{l}5 / 12(41 \cdot 6 \%) \\
10 / 20(50 \%) \\
10 / 17(58 \cdot 8 \%) \\
10 / 32(33 \cdot 2 \%)\end{array}$ & $\begin{array}{l}7 / 112(6 \cdot 3 \%) \\
14 / 173(8 \cdot 1 \%) \\
12 / 58(20 \cdot 7 \%) \\
14 / 258(5 \cdot 4 \%)\end{array}$ \\
\hline
\end{tabular}


could be transmitted via sexual contact and $91 \%$ knew that transmission could be prevented by the use of condoms. However, only $71 \%$ thought that heterosexuals were at risk of infection and only $74 \%$ knew whether HIV was present in the country to which they were travelling. ${ }^{14}$

All HIV positive heterosexuals identified in this study had visited sub-Saharan Africa, and similar observations have been made in genitourinary medicine clinics in London. ${ }^{15}$ With the rapidly increasing HIV seroprevalence in other popular tourist destinations (for example Thailand, parts of India), it is likely that in future increasing numbers of travellers will be infected in other geographical regions.

We recommend that anyone travelling abroad should be given specific advice relating not only to HIV transmission and its prevention, but also to sexual health in general. We found that virtually three quarters of heterosexual travellers requesting an HIV test had at least one sexual partner from a country in which HIV is commonly transmitted by heterosexual intercourse. This study emphasises the importance of educating the travelling public about the risks of heterosexual HIV transmission.
1 Evans BG, Noone A, Mortimer JY, et al. Heterosexually acquired HIV-1 infection: cases reported in England, Wales and Northern Ireland, 1985 to 1991. Communicable Disease Report 1992 (April);2:R49-55.

2 Communicable Disease Surveillance Centre. Communicable Disease Report 1991 (June);1:R69-R76.

3 Mitchell S, Band B, Bradbeer B, Barlow D. Imported heterosexual HIV infection in London. Lancet 1991;337:1614-5.

4 O'Farrell N, Allen M, Gardner F. Imported heterosexual HIV infection. Lancet 1991;338:386-7.

5 Nandwani R, Hawkins D, Barton S. Imported heterosexual HIV infection. Lancet 1991;338:387.

6 Evans B, McLean K. Imported heterosexual HIV infection. Lancet 1991;338:387.

7 Godley MJ. Imported heterosexual HIV infection. Lancet 1991;338:387.

8 Brook MG, Barnes A, Cook GC, Mabey DCW. A typhus like illness caused by acute HIV seroconversion. Postgrad Med f 1991;67:92-3.

9 Gorney BP, Craske J, Turner AJL. Human immunodeficiency virus infection acquired in Thailand. $\mathcal{f}$ Infect 1990;3:264.

10 Bonneux L, Van der Stuyft P, Taelman H, et al. Risk factors for infection with human immunodeficiency virus among for infection with human immunodeficiency virus among

11 Business Monitor, Overseas Travel and Tourism. Central Statistical Office. MA6 HMSO, London 1989.

12 Houweling H, Coutinho RA. Risk of HIV infection among Dutch expatriates in sub-Saharan Africa. Int $\mathcal{Y} S T D$ and AIDS 1991;2:252-7.

13 Cappello M, Bernard KW, Jones B, Francis H, Van der Vlugt $T$. Human immunodeficiency virus infection among Vlugt T. Human immunodeficiency virus infection among Peace Corps volunte

14 Porter, JDH, Phillips-Howard PA, Behrens, RH. AIDS Awareness Among Travellers. Travel Medicine International 1991;2:28-32.

15 Ainsworth JG, Murphy SM, Harris JRW. Imported heterosexual HIV infection. BMf 1991;303:1060-1. 